\title{
Molecular phylogeny of cave dwelling Eremogryllodes crickets (Orthoptera, Myrmecophilidae) across Zagros Mountains and Southern Iran
}

\author{
Mohadeseh S. Tahami (D) ${ }^{1}$, Mina Hojat-Ansari (D) ${ }^{2}$, Anna Namyatova (D) ${ }^{3}$, \\ and Saber Sadeghi (D) ${ }^{{ }^{*}}$ \\ ${ }^{1}$ Entomology Research Laboratory, Biology Department, Adabiat St., Shiraz University, 7146713565, Shiraz, Iran \\ ${ }^{2}$ Gastroenterohepatology Research Center, Shiraz University of Medical Sciences, Khalili St., Shiraz, Iran \\ ${ }^{3}$ Chromas Research Resource Center, Saint Petersburg State University, Oranienbaumskoye sh. 2, 198504, Saint Petersburg, Russia
}

\begin{abstract}
Recently, several new species and subspecies from the genus Eremogryllodes Chopard, 1929 (Insecta: Orthoptera: Myrmecophilidae) inhabiting caves of Iran, have been described based on morphology. The high variation of genitalia structure along with high similarity of external morphology between populations hamper the precise species identification. Thus, molecular approaches are critical to determine the taxo-nomic positions of species/subspecies of this genus. Here we provide the molecular phylogeny, based on the 16S rRNA mitochondrial gene, of recently described species of Eremogryllodes along with some uni-dentified specimens from the same region. The results support the monophyly of the family Myrmecophi-lidae. The topology of the $16 \mathrm{~S}$ rRNA tree did not completely support the five morpho-species. The three main recovered clades mainly grouped specimens by their geographical locations. Our study suggests the possi-bility of more than one species in one cave and the presence of cryptic species among cave dwelling crick-ets, based on the 16S rRNA marker.
\end{abstract}

Keywords: Iran, Orthoptera, cave crickets, Eremogryllodes, 16S rRNA, phylogeny

Received 17 October 2020; Revised 9 June 2021; Accepted 9 June 2021

Citation: Tahami, M.S., Hojat-Ansari, M., Namyatova, A., Sadeghi S., 2021. Molecular phylogeny of cave dwelling Eremogryllodes crickets (Orthoptera, Myrmecophilidae) across Zagros Mountains and Southern Iran. International Journal of Speleology, 50(2), 213-221.

https://doi.org/10.5038/1827-806X.50.2.2360

\section{INTRODUCTION}

Myrmecophilidae (Insecta: Orthoptera), or antloving crickets, together with the mole crickets, Gryllotalpidae, are located in the superfamily Gryllotalpoidea. This family is divided into two subfamilies, Myrmecophilinae and Bothriophylacinae. Eremogryllodes is the genus inside Bothriophylacinae, tribe Bothriophylacini, with 11 described species (Chopard 1948, 1968; Gorochov 1979, 1980; Cigliano et al., 2020). The taxonomic position of Eremogryllodes has been under discussion for a long time. It was placed inside the family Gryllidae, between Gryllomorphinae and Phalangopsinae (Chopard, 1929), at first, but later its position was considered between Myrmecophilinae and Mogoplistinae (still inside Gryllidae) (Chopard, 1934), based on superficial similarities. Later on, the genus was placed in Mogoplistinae until it was eventually resurrected in Myrmecophilidae: Bothriophylacinae: Bothriophylacini (Tahami et al., 2017). Its latest taxonomical position was based on similarities of specialized features such as the structure of the epiphallus and more developed plates of ecto- and endoparameral apodems, with the other genus of this tribe, Bothriophylax (Tahami et al., 2017).

Eremogryllodes is a poorly-known genus of Myrmecophilidae and it is only reported from North Africa, southwest and Central Asia. Until recently, no substantial review of Eremogryllodes and its subfamily, Bothriophylacinae was available (Tahami et al., 2017). Members of this genus mostly inhabit caves and burrows of rodents and reptiles. They have a miniature body with milky to white colour that perfectly camouflages the crickets on the cave walls. These morphological characteristics along with its cryptic lifestyle hamper the collection of the specimens which may be why the genus has not received considerable attention by taxonomists and the true geographic range of Eremogryllodes remains unclear. Recently, six new species and three subspecies of genus Eremogryllodes from caves 
of Iran were described (Tahami et al., 2017, 2018). All recorded populations have been collected inside caves, e.g., cave walls, arch, and crevices, near the entrance to the furthest middle zone of the cave, sometimes referred as parahypogean zone (Prous et al., 2004; Tahami et al., 2016). There are no data on the life cycle of Eremogryllodes species and other biological aspects of their life however, we assume that the populations of Iranian Eremogryllodes are very restricted to their natural habitats, as we didn't encounter individuals outside the cave environment during our sampling. The close opposition and the lack of hybrid zone between cave dwelling populations has been extensively discussed in Hubell and Norton (1978). Even when leaving caves at nights, crickets' spatial distribution is mainly limited to feeding or mating in close distance to their habitat (Hubell \& Norton, 1978; Carchini et al., 1995). These characteristics specific to cavernicolous crickets can hinder gene exchange between populations. However, more studies need to be carried out to confirm this assumption for cave-dwelling Eremogryllodes taxa.

Organisms living in caves with similar environmental factors, such as darkness, high humidity, stable temperature range throughout the year, and poor food resources, undergo convergent evolution (Culver et al., 1995; Culver \& Pipan, 2009a). This phenomenon is also resonated in cave dwelling populations of Eremogryllodes meaning that they exhibit highly similar external morphology to each other. This feature along with their high variation of genitalic features within and between populations have made any attempt of accurate species delineation difficult. Therefore, molecular studies are essential to more reliably delineate species.

Until now, only the genus Myrmecophilus has been included in all phylogenetic studies of Ensifera, as the representative of family Myrmecophilidae (Zhou et al., 2010; Song et al., 2015; ChintauanMarquier et al., 2016; Zhou et al., 2017). In the current research, we had the opportunity to include sequences of Eremogryllodes populations for the first time from caves of Iran. We aim to test the relationship between the two subfamilies of Myrmecophilidae; Myrmecophilus as the representative of Myrmecophilinae, and Eremogryllodes as the representative of Bothriophylacinae. We base our current research on species described in Tahami et al. $(2017,2018)$, collected by the first author (MT) in the Iranian Zagros Mountains and a part of southern Iran using 16S mitochondrial gene. The mitochondrial 16S rRNA gene is considered to be informative for closely related cricket taxa (Taylan et al., 2013; Taylan $\&$ Sirin, 2016). Therefore, the current study has three main aims: (1) to test whether the described morphospecies correspond to the molecular evidence, (2) to test for the presence of cryptic species and (3) to test the monophyly of Myrmecophilidae.

\section{MATERIAL AND METHODS}

\section{Sample collection}

A vast and extensive cave survey was carried out throughout the entire Zagros ranges and some provinces in the south of Iran. Specimens were collected by fine brush, hand, and aspirator and were preserved in absolute ethanol for molecular studies. In total, 56 caves were investigated and Eremogryllodes specimens were collected from 32 caves. A distribution map of the caves is given in Fig. 1. We aimed to amplify $16 \mathrm{~S}$ mitochondrial rRNA gene region for representatives of five out of the six species described in Tahami et al. (2017, 2018): Eremogryllodes dilutus, E. iranicus, E. persicus, E. bifurcatus and E.

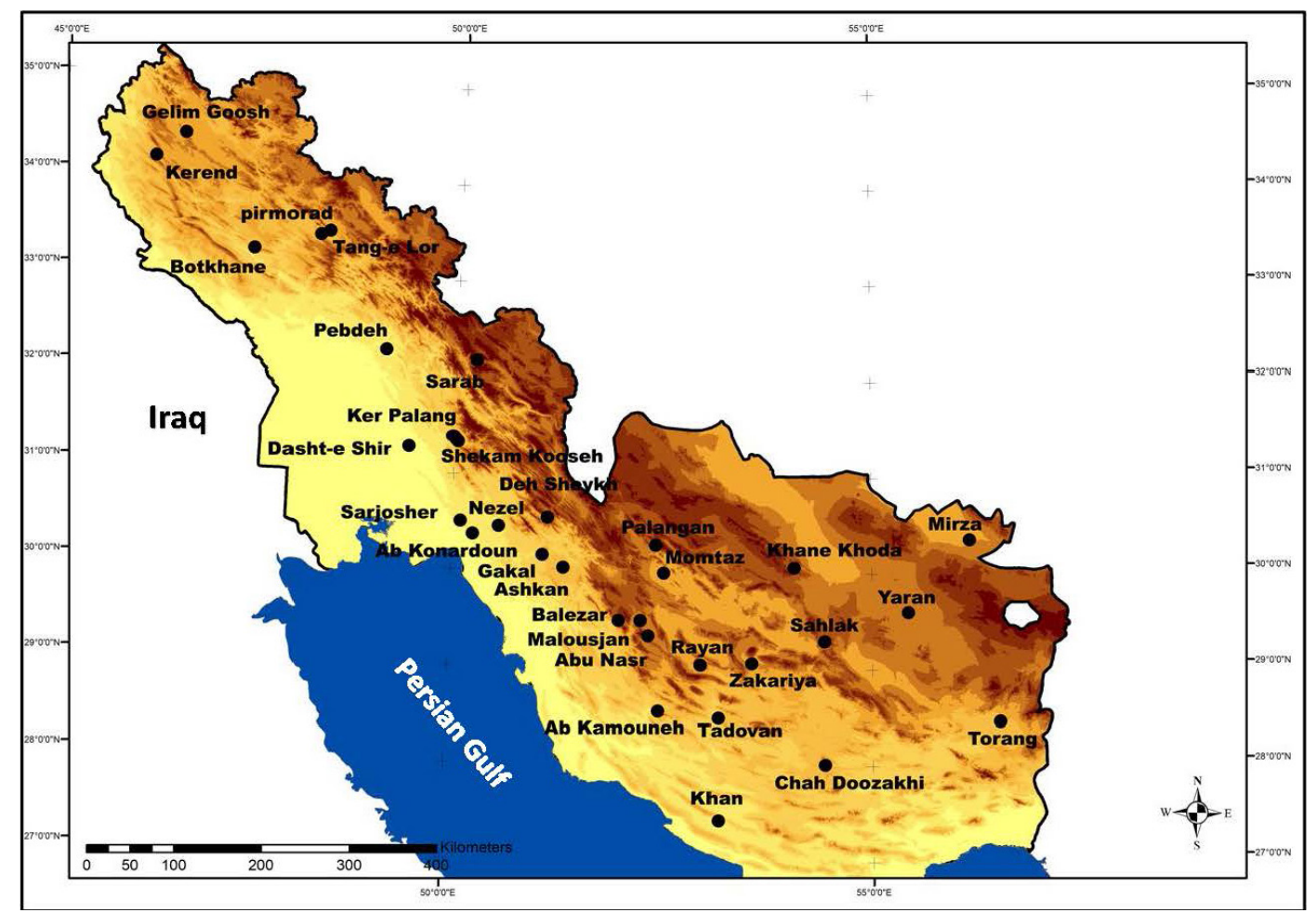

Fig. 1. Distribution map of the cave localities for sampled Eremogryllodes specimens, the map includes Zagros Mountain ranges and two provinces in the south of Iran (Yazd and Kerman provinces). 
spinulatus. Furthermore, we included 20 immature specimens from Sarjosher, Zakariya, Ashkan, Gakal, Abu Nasr, Rayan, Yaran, and Chah Doozakhi caves. Although the attempt of specimen collection for those caves was made more than once and at different times, we were not able to find mature males. In some cases, we captured males that seemed to be mature judging from their size, but abdomens were empty of any mating apparatus. The developmental mechanisms of this morphological peculiarities is not clear however, it is possible that in these populations, the sub-adult stage is rather long (longer than one year) as is seen in cave-dwelling Dolichopoda species (Di Russo, 1987; Carchini et al., 1994). A total of 48 specimens of Eremogryllodes were subjected to $16 \mathrm{~S}$ rRNA studies. To check the monophyly of the genus Eremogryllodes and its family, Myrmecophilidae, we included sequences of Myrmecophilidae (Myrmecophilus), Gryllotalpidae (Grylloyalpa), Mogolistidae (Ornebius), and Gryllidae (Gryllus) along with Melnopus sanguinipes (Acrididae) as a distant outgroup available in Genbank (www.ncbi. nlm.nih.gov). Table1 and Supplementary Table S1 provide the accession numbers of all sequences included in the analysis.

Table 1. Profile of Eremogryllodes samples used in this study with their Genbank accession numbers for 16S rRNA.

\begin{tabular}{|c|c|c|c|c|c|}
\hline No. & $\begin{array}{l}\text { Voucher } \\
\text { Code }\end{array}$ & $\begin{array}{c}\text { Accession } \\
\text { Code-16S }\end{array}$ & Morphological species attribution & Cave & Locality \\
\hline 1 & M1994 & MH266701 & Eremogryllodes dilutus & Balezar & Fars Prov. \\
\hline 2 & M1627 & MH266702 & Eremogryllodes dilutus & Ab Konardoon & Khuzestan Prov. \\
\hline 3 & M1965 & MH266703 & Eremogryllodes dilutus & Ab Konardoon & Khuzestan Prov. \\
\hline 4 & M1990 & MH266704 & Eremogryllodes dilutus & Ab Konardoon & Khuzestan Prov. \\
\hline 5 & M1628 & MH266705 & Eremogryllodes dilutus & Deh Sheykh & Kohgiluye \& Buyerahmad Prov. \\
\hline 6 & M19105 & MH266706 & Eremogryllodes dilutus & Deh Sheykh & Kohgiluye \& Buyerahmad Prov. \\
\hline 7 & M1995 & MH266707 & Eremogryllodes dilutus & Deh Sheykh & Kohgiluye \& Buyerahmad Prov. \\
\hline 8 & M1724 & MH266708 & Eremogryllodes dilutus & Dasht-e Shir & Khuzestan Prov. \\
\hline 9 & M19101 & MH266709 & Eremogryllodes dilutus & Ker Palang & Khuzestan Prov. \\
\hline 10 & M1624 & MH266710 & Eremogryllodes dilutus & Pebdeh & Khuzestan Prov. \\
\hline 11 & M1629 & MH266711 & Eremogryllodes dilutus & Sarab & Ilam Prov. \\
\hline 12 & M1562 & MH266712 & Eremogryllodes dilutus & Momtaz & Fars Prov. \\
\hline 13 & M1561 & MH266713 & Eremogryllodes iranicus & Khane Khoda & Yazd Prov. \\
\hline 14 & M1744 & MH266714 & Eremogryllodes iranicus & Khane Khoda & Yazd Prov. \\
\hline 15 & M1720 & MH266715 & Eremogryllodes iranicus & Ab Kamouneh & Fars Prov. \\
\hline 16 & M1625 & MH266716 & Eremogryllodes iranicus & Malousjan & Fars Prov. \\
\hline 17 & M1997 & MH266717 & Eremogryllodes iranicus & Malousjan & Fars Prov. \\
\hline 18 & M1938 & MH266718 & Eremogryllodes bifurcatus & Gelim Goosh & Kermanshah Prov. \\
\hline 19 & M1979 & MH266719 & Eremogryllodes bifurcatus & Botkhane & Kermanshah Prov. \\
\hline 20 & M1982 & MH266720 & Eremogryllodes bifurcatus & Pirmorad & Lorestan Prov. \\
\hline 21 & M1943 & MH266721 & Eremogryllodes bifurcatus & Kerend & Kermanshah Prov. \\
\hline 22 & M1626 & MH266722 & Eremogryllodes persicus & Tadovan & Fars Prov. \\
\hline 23 & M02 & MH266724 & Eremogryllodes $s p$. & Zakariya & Fars Prov. \\
\hline 24 & M1680 & MH266725 & Eremogryllodes $s p$. & Zakariya & Fars Prov. \\
\hline 25 & M1987 & MH266732 & Eremogryllodes $s p$. & Zakariya & Fars Prov. \\
\hline 26 & M19104 & MH266729 & Eremogryllodes sp. & Zakariya & Fars Prov. \\
\hline 27 & M1681 & MH266726 & Eremogryllodes $s p$. & Ashkan & Fars Prov. \\
\hline 28 & M1985 & MH266731 & Eremogryllodes sp. & Ashkan & Fars Prov. \\
\hline 29 & M1950 & MH266730 & Eremogryllodes sp. & Rayan & Fars Prov. \\
\hline 30 & M1991 & MH266733 & Eremogryllodes spinulatus & Chah Doozakhi & Fars Prov. \\
\hline 31 & M1998 & MH266736 & Eremogryllodes spinulatus & Chah Doozakhi & Fars Prov. \\
\hline 32 & M19100 & MH266728 & Eremogryllodes spinulatus & Chah Doozakhi & Fars Prov. \\
\hline 33 & M1996 & MH266735 & Eremogryllodes sp. & Gakal & Kohgiluye \& Buyerahmad Prov. \\
\hline 34 & M1999 & MH266737 & Eremogryllodes $s p$ & Gakal & Kohgiluye \& Buyerahmad Prov. \\
\hline 35 & M1980 & MH347906 & Eremogryllodes iranicus & Sahlak & Fars Prov. \\
\hline 36 & M1972 & MH347907 & Eremogryllodes iranicus & Sahlak & Fars Prov. \\
\hline 37 & M1947 & MH347908 & Eremogryllodes bifurcatus & Tang-e_Lor & Lorestan Prov. \\
\hline 38 & M1948 & MH347909 & Eremogryllodes bifurcatus & Tang-e_Lor & Lorestan Prov. \\
\hline 39 & M1719 & MH266723 & Eremogryllodes persicus lari & Khan & Fars Prov. \\
\hline 40 & M1958 & MH347910 & Eremogryllodes persicus lari & Khan & Fars Prov. \\
\hline 41 & M1722 & MH347911 & Eremogryllodes dilutus & Shekam_Kooseh & Khuzestan Prov. \\
\hline
\end{tabular}




\begin{tabular}{|l|l|l|c|c|c|}
\hline 42 & M1945 & MH347912 & Eremogryllodes dilutus & Palangan & Fars Prov. \\
\hline 43 & M1934 & MH347913 & Eremogryllodes dilutus & Palangan & Kerman Prov. \\
\hline 44 & M1957 & MH347914 & Eremogryllodes persicus torangae & Torang & Kerman Prov. \\
\hline 45 & M1952 & MH347915 & Eremogryllodes $s p$. & Yaran & Khuzestan Prov. \\
\hline 46 & M1954 & MH347916 & Eremogryllodes $s p$. & Sarjosher & Khuzestan Prov. \\
\hline 47 & M1955 & MH347917 & Eremogryllodes $s p$. & Sarjosher & Fars Prov. \\
\hline 48 & M1992 & MH266734 & Eremogryllodes $s p$. & Abu Nasr & \\
\hline
\end{tabular}

\section{DNA extraction and sequencing technique}

DNA was extracted from the hind leg using a local animal extraction kit (Dena Zist Asia, Mashhad, Iran), and Qiagen DNeasy DNA Blood \& Tissue Kit (QUIAGEN). For amplification, we used PCR protocol according to Robillard and Desutter-Grandcolas (2006) with some modifications of annealing temperature and cycle duration (Table 2). We used primers specifically designed for Myrmecophilus 16S rRNA fragment (Robillard and DesutterGrandcolas 2006). Generally, a 388-431 base pairs (bps) fragment of the mitochondrial 16S rRNA was amplified through the polymerase chain reaction (PCR) by Bioer, XP cycler (BIOER), and Bio-RAD MjMini thermal cycler (Bio-RAD). Amplification was performed in the $25-\mu 1$ volume containing $0.5-1 \mu \mathrm{l}$ of each primer $(100 \mathrm{mM}), 3-5 \mu \mathrm{l}$ DNA template of each sample, and $12.5 \mu 1$ of $2 \mathrm{X}$ PCR Master Mix, Genetbio, Cat. no. G-2000 (including dNTP, MgCl2, PCR buffer and Taq DNA polymerase). An initial duration or equal 5-10 min at $94^{\circ} \mathrm{C}$ was applied. A positive control was added in each PCR run to check for possible errors. Double-stranded amplified DNAs were checked for the presence and quality of the desired gene segment using 1\% agarose gel electrophoresis. PCR products were initially sent for single-strand sequencing with the forward primer, however, the reverse strands were also sequenced to clarify the observed ambiguous sites in some samples. PCR purification and sequencing were carried out in Macrogen (Korea), Research Resource Center Molecular and Cell Technologies (St. Petersburg State University, Russia) and Dr. Faghihi genetic lab (Bayan Gen Pars Institute, Shiraz- Iran).

Table 2. PCR protocol and primers used for 16S rRNA marker.

\begin{tabular}{|c|c|c|c|c|c|}
\hline Primer $^{1}$ & Sequence $\left(5^{\circ}-3^{\prime}\right)$ & Denaturation & Annealing & Cycles & Final Elongation \\
\hline $16 \mathrm{SAG}$ & CGCCTGTTTATCAAAAACATGT & \multirow{2}{*}{$30 \mathrm{~s}$ at $94^{\circ} \mathrm{C}$} & \multirow{2}{*}{$40 \mathrm{~s}$ at $55^{\circ} \mathrm{C}$} & \multirow{2}{*}{$36-40$} & \multirow{2}{*}{$7 \mathrm{~min}$ at $72^{\circ} \mathrm{C}$} \\
\hline $16 \mathrm{SBG}$ & AGATCACGTAAGAATTTAATGGTC & & & & \\
\hline
\end{tabular}

${ }^{1}$ Robillard and Desutter-Grandcolas (2006)

\section{Alignment and phylogenetic analysis}

Sequences were edited using BioEdit 7.2.5 software (Hall et al., 2011), and aligned using Clustal W algorithm, as implemented in software packages Molecular Evolutionary Genetics Analysis (MEGA) v6 (Tamura et al., 2011) and then manually checked. In some cases, sequences with a high amount of nucleotide ambiguity and/if the sequences did not blast with orthopteran mitochondrial genes, they were considered errors and removed from further analyses. Two separate phylogenetic trees were reconstructed by Maximum likelihood (ML) and Bayesian inference (BI) methods using CIPRES Science Gateway (Miller et al., 2010). For Bayesian analysis, we first applied the model test implemented in PAUP* version 4.0b10 (Swofford, 2002) and MrModeltest2 (Nylander, 2004) software. The model for $16 \mathrm{~S}$ matrix revealed as GTR $+\mathrm{I}+\mathrm{G}$, out of 24 models of nucleotide substitution. The alignment was converted to the Nexus format using the Mesquite software (Maddison, 2018) to run the Bayesian analysis. Bayesian analysis was done through the CIPRES Science Gateway, using MrBayes on XSEDE (3.2.6) interface, with 50000000 generations for the total of $6616 \mathrm{~S}$ sequences. The Maximum Likelihood analysis was performed 10 times with different random seeds each time, using RAxML-HPC v.8 on XSEDE (8.2.10) package with the maximum bootstrap number of 1000 replicates. The corresponding outputs were visualized using FigTree 1.4.3 (Drummond \& Rambaut, 2007). To have a better visualization of how samples are phylogenetically clustered with regard to their geographical location, we projected the phylogenetic tree of Eremogryllodes on the geographic map of cave localities obtained from DIVA-GIS 7.5.0 (http://www.diva-gis.org/gdata) in CorelDRAW 2019, version 21.1.0.643.

\section{Genetic diversity}

Factors of genetic diversity including nucleotide diversity $(\pi)$, number of haplotypes (h), and genetic distance (Fst) were calculated using the program DnaSP V.5.0 (Librado \& Rozas, 2009).

\section{RESULTS}

Forty-eight sequences of $16 \mathrm{~S}$ rRNA from Eremogryllodes voucher specimens were successfully amplified and aligned. Samples information are given in Table 2. Eighteen additional 16s rRNA sequences from families discussed in the introduction (Myrmecophilus, Gryllus, Gryllotalpa, Ornebius) plus Melanoplus sanguinipes, as an outgroup, were extracted from Genbank (Supplementary Table S1). These families are included because of the controversies over the real position of Eremogryllodes during past decades (refer to introduction). In the present study, the final number of sites (excluding fixed gaps/missing data) for $16 \mathrm{~S}$ is $360 \mathrm{bps}$ of which 212 are invariable, 148 are variable (polymorphic) and 115 are parsimony informative. 


\section{Phylogeny}

The general topology of the Bayesian (BI) tree corresponds to the maximum likelihood (ML) tree for our 16S rRNA marker (Fig. 2 and Supplementary Fig. S1) hence, we chose to focus only on the BI tree. Among all included taxa in this study, Eremogryllodes specimens are clustered with those of Myrmecophilus. Within the Eremogryllodes lineage, three wellsupported clades are recovered (Fig. 2). Clade A includes only E. bifurcatus and is separated from the two other clades with high bootstrap support (BS) of $100-88$ (BI-ML), the only exception for this species is specimens of Tang-e Lor cave that are located within
Clade B. Specimens of $E$. dilutus are mainly clustered into clade $\mathrm{B}$, but $E$. dilutus from Palangan and Dasht-e Shir caves are placed in clade C. Clade B has high support of 99-82 (BI-ML), and also contains unidentified specimens from Sarjosher, Zakariya, Ashkan, and Gakal caves. Clade $\mathrm{C}$ is a mix of $E$. iranicus, E. persicus, and E. spinulatus, plus E. dilutes from the two mentioned caves and $E$. bifurcates from Tang-e Lor cave. Other unidentified specimens from Sahlak, Yaran, Chah Doozakhi and Sarjosher caves, are also placed in clade C. Among these, almost all specimens of $E$. iranicus are grouped in one sub-clade except the one from Sahlak cave.

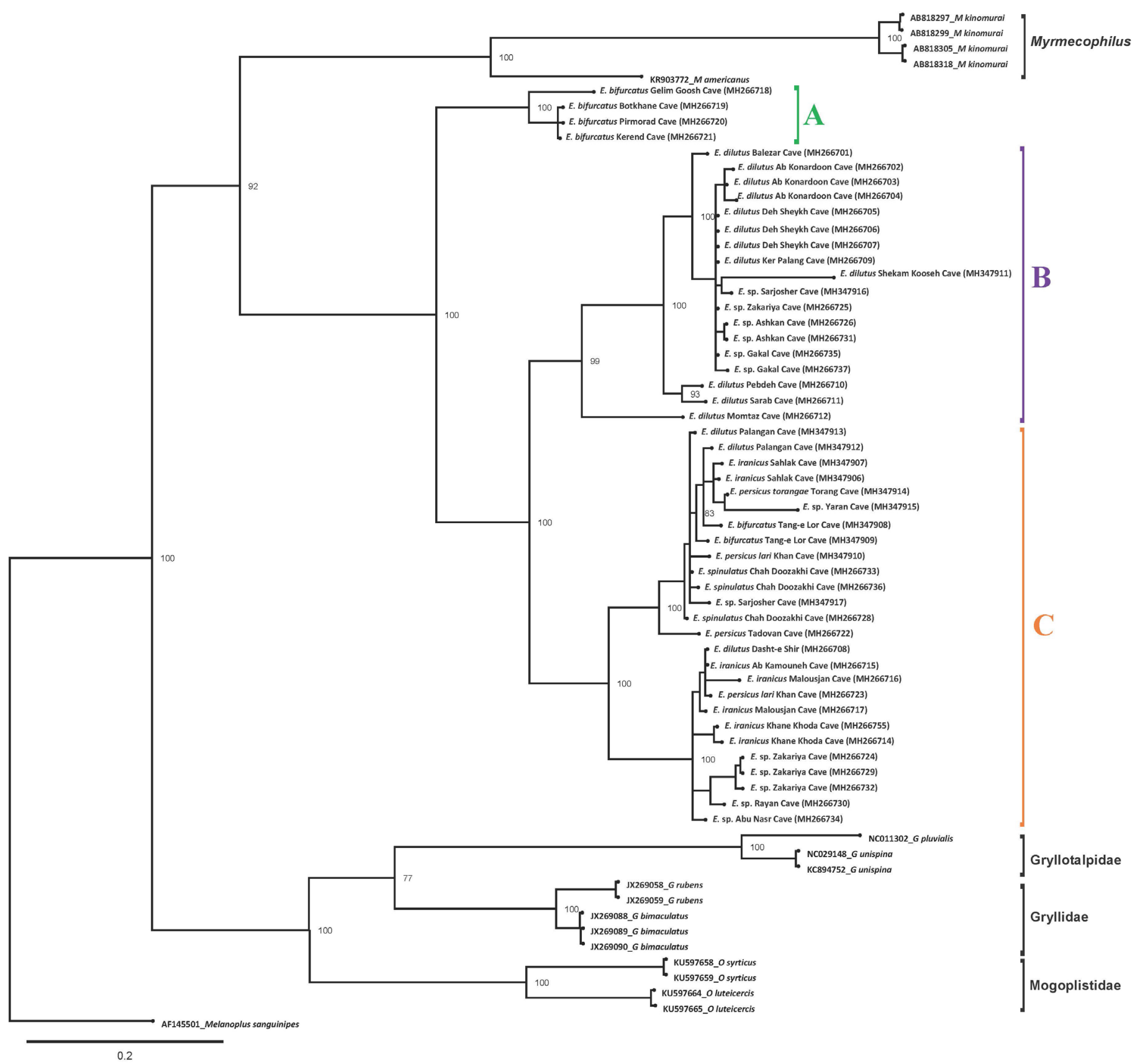

Fig. 2. Phylogeny of four families of crickets, Myrmecophilidae, Gryllotalpidae, Mogoplistidae, and Gryllidae, based on 16S rRNA marker, obtained by Bayesian inference. Support values are given at each node. The tree is rooted on Melanoplus sanguinipes. Species name, cave name, and accession number are provided at the tip of the tree.

According to Figure 3, Clade A covers Northern Zagros, clade $\mathrm{B}$ mostly covers the central zone, and clade $\mathrm{C}$ mostly covers southern Iran (including Southern Zagros, and regions outside the Zagros ranges in Yazd and Kerman Prov.). There is an overlap between the distributional region of clades $\mathrm{B}$ and $\mathrm{C}$; specimens from Ashkan, Balezar and Momtaz caves and one specimen from Zakariya cave (Fars Prov.) are grouped in clade B while all the rest of caves from Fars Province and southern regions in Iran (Kerman and 
Yazd Prov.) belong to clade C. Likewise the geographic distribution range of specimens belonging to clade $\mathrm{C}$ are extended northward e.g., specimens from Dasht-e Shir, Sarjosher, and Tang-e Lor caves.

\section{Genetic diversity}

Nucleotide Diversity (ND) was calculated at 0.122 (п), number of haplotypes $38(\mathrm{H})$, and haplotype diversity 0.985 (HD). The genetic distance $\left(\mathrm{F}_{\mathrm{st}}\right)$ between the five included morphological species was calculated at 0.416 , and between the three phylogenetic clades recovered in this study was calculated at 0.716 .

\section{DISCUSSION}

\section{Taxonomic status of Myrmecophilidae}

In the present study, the $16 \mathrm{~S}$ rRNA marker strongly supports the monophyly of Myrmecophilidae. In recent phylogenetic studies of Ensifera, Myrmecophilidae showed a close affinity with Gryllotalpidae (Zhou et al., 2010; Chintauan-Marquier et al., 2015). This phylogenetic relationship is not recovered in the current study. However, we should keep in mind that only Myrmecophilus used to be included as the representative of the family Myrmecophilidae. It is also possible that this topology is due to an incomplete data set and including all cricket taxa may change the current phylogenetic position of Myrmecophilidae.

\section{Phylogeny of Eremogryllodes}

The phylogenetic analysis revealed that all Eremogryllodes samples are clustered together with 99 percent of bootstrap support in BI tree. The supporting values for each clades and sub-clades were also high (BS $=100$ in most cases). In our BI tree, three main clades are recovered which could only partially separate the five morpho-species from each other. Most of the samples attributed to E. bifurcates, morphologically, are clustered into clade A, excluding only Tang-e Lor cave. Likewise, clade B comprises most of the members of $E$. dilutus from various caves except for Palangan and Dasht-e Shir caves. Members of E. iranicus, E. persicus and E. spinulatus could not be recovered as separate species as they are grouped in clade $\mathrm{C}$.

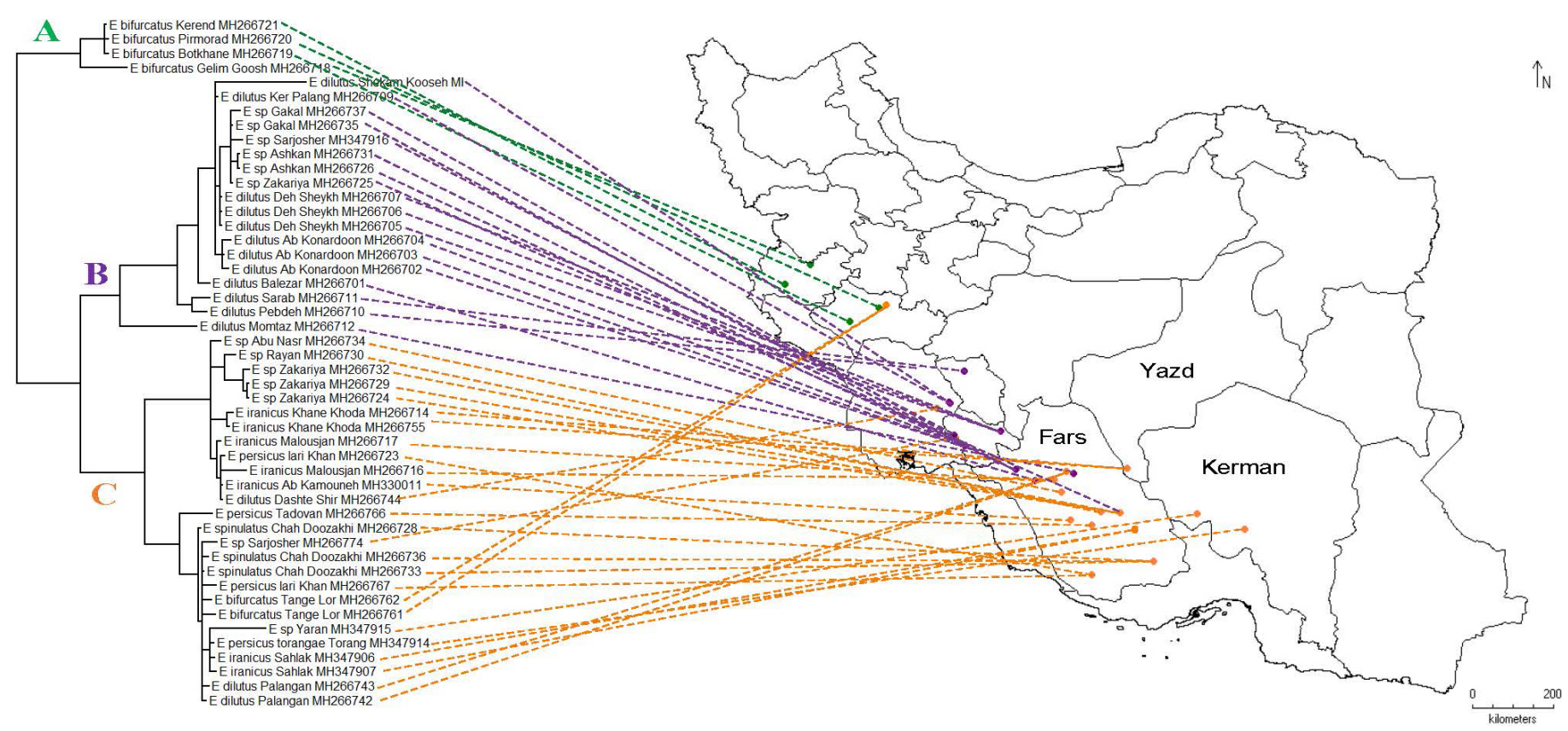

Fig. 3. Phylogenetic tree of Eremogryllodes projected on the geographic map of the sample locations showing the distribution of molecular species. Species name, cave name, and accession number are provided at the tip of the tree.

Our phylogenetic tree suggests that molecular species tend to be clustered geographically, as close caves are mostlyclustered within one clade (Fig. 3), albeit exceptions for clades $\mathrm{B}$ and $\mathrm{C}$ are noticeable with clade $\mathrm{B}$ having an extension southward and clade C northward. Clade A showed a clear separated distribution zone but the geographical lines between clades B and $\mathrm{C}$ was not clear.

The sample from Dasht-e Shir cave has been proposed as a subspecies of Eremogryllodes dilutus (E. d. bakhtiyari) (Tahami et al., 2017). Based on our molecular result, it can even be considered as distant as a new species. Morphological variations of the body colour pattern, distal part of the genital plate, and the differences in genitalia, described in Tahami et al. (2017) also support this idea. However, we would need more sequences from the putative $E$. d. bakhtiyari to be able to make a strong statement over its genetic distance and taxonomy. The separated specimens of Palangan and Tang-e Lor caves, E. dilutus and E. bifurcates, respectively, can represent cryptic species as no discriminating morphological characteristics could be found to exclude them from their conspecies. This scenario is highly likely as convergent evolution resulting from exposure to similar selection pressures can produce cryptic species, therefore, two genetically different species are given one name due to their morphological similarities (Wiens et al., 2003; Pfenninger \& Schwenk, 2007). Cryptic species has been reported for Myrmecophilus, which lives inside ant nests, and for cave populations of the cricket family, Rhaphadiphoridae (Taylor et al., 2007; Komatsu et al., 2008).

Overall, the observed variation within populations of cave-dwelling cricket species across different localities is not a strange phenomenon. This might simply be 
due to microhabitat variation and different ecological factors that affect the genetic diversification (Fujisawa, et al., 2015). Incomplete lineage sorting of the mitochondrial gene is another factor that might affect the phylogenetic placement of different specimens (Funk \& Omland, 2003). Introgression could also be considered as a reason; however, it is less likely, as caves are known to be isolated calcrete aquifers under the ground, which is equivalent to oceanic islands, the 'subterranean island (archipelago) hypothesis' (Cooper et al., 2007; Juan et al., 2010), and isolated habitats above the ground with the surface act like an ocean of different environmental variables, sunlight, and predators (Culver \& Pipan, 2009b), all of which prevent free movement of subterranean species between caves, thus reducing the gene flow . This is also supported by the high level of genetic distance ( $\mathrm{F}_{\mathrm{St}}$ ) in both cases (between species: 0.416, between lineages: 0.746) which indicates almost no gene flow. Previous studies on the genetic structure of Dolichopoda have indicated relatively high genetic divergence and low gene flow even between conspecific populations (Allegrucci et al., 1987, 1997). The other noticeable result is the placement of the two individuals of $E$. persicus lari from Khan cave in two different clades. A similar situation can be seen for unidentified specimens of Zakariya and Sarjosher caves. The phylogenetic separation of specimens from one cave locality may be due to the fact that genetic diversity within populations of cavedwelling crickets are generally higher than normal (Taylor et al., 2007). The relatively high HD for $16 \mathrm{~S}$ $(0.95)$ indicates that multiple haplotypes can exist in one cave population but then will be placed within a genetically divergent group in the phylogenetic tree (Taylor et al., 2007). On the other hand, it is also probable that the separated specimen from Khan cave is a cryptic species, as there were no significant differences between the two specimens of Khan cave. The occurrence of substantial genetic diversity inside the cave populations, and the presence of more than one species inside one cave (i.e., cryptic species) has been observed in many cases (Buhay \& Crandall, 2005; Finlay et al., 2006; Lejeusne \& Chevaldonné, 2006; Taylor et al., 2007; Komatsu et al., 2008; Guzik et al., 2009). Finally, with regard to our collection of Iranian cave dwelling Eremogryllodes which show a wide range of variable features in their morphology and genitalia from cave to cave, morphological traits might not be a robust indicator for the species delineation in this case. One reason is the molecular clustering of E. iranicus, E. persicus, and E. spinulatus together. Moreover, populations of $E$. dilutus from the caves Pebdeh, Deh Sheykh, Balezar, Ab Konardoun, and Ker Palang, although show substantial variations in the coloration, hind tibiae armament, distal part of the genital plate, and the genital structures such as distal part of rachis, endoparameral sclerites, and ectoparameres, are clustered together with the holotype (type locality: Momtaz cave) in clade A. On the other hand, members of Palangan cave are left outside the clade A while no noticeable variation could be diagnosed between those specimens and the holotype. However, we should not exclude the fact that having only a fraction of the mitochondrial gene marker (incomplete lineage sorting) and the possibility of human error in DNA amplification process and sequencing error could have affected our final results.

\section{CONCLUSION}

In the current study, specimens of genus Eremogryllodes have been subjected to molecular studies for the first time. As a result, the monophyly of Myrmecophylidae was supported. The 16S rRNA marker could only partially separate the morphospecies, however, with variations inside clades. This emphasis the need to adding more mitochondrial and nuclear gene markers in order to recover a higher resolution phylogeny. Moreover, it was suggested that the presence of cryptic species in some caves are highly probable. Here, we treat our results preliminary as further molecular studies, more preferably using next generation sequencing approach, are required to shed light on the robust taxonomic status of newlydescribed species.

\section{ACKNOWLEDGMENTS}

We thank the Iranian Caving Club and the local guides for their technical help in caving and specimen collections. We thank Aleksandr Dyomin, Svetlana Galkina, Roozbehan Khaefi, and Golnaz Sayyadzadeh for their kind cooperation in the process of sequencing, alignments, sequence submission, and data analysis. We would like to thank Dr. Saeid Negahban for providing the distribution map of the cave localities by Arc GIS. We are deeply grateful to Alsu Saifitdinova for her kind advice and for providing the opportunity for M.T to work in the Chromas research complex in St. Petersburg, Russia. A part of DNA extraction and amplification was done in the molecular laboratory of Islamic Azad University of Kerman. The Iran National Science Foundation (INSF) is appreciated for partial financial support of the study. Last but not least, we would like to thank unknown reviewers for their careful review and valuable inputs to the original manuscript.

Authorship statement: SS and MT designed and directed the study. $\mathrm{MH}$, and AN collaborated with MT in molecular lab work and data analyzing. MT and SS carried out the caving and data collection as well as writing the paper with input from all authors. All authors contributed to the interpretation of the results and refinement of the final manuscript.

\section{REFERENCES}

Allegrucci, G., Cesaroni, D., Sbordoni, V., 1987. Adaptation and speciation of Dolichopoda cave crickets (Orthoptera, Rhaphidophoridae): geographic variation of morphometric indices and allozyme frequencies. Biological Journal of the Linnean Society, 31, 151-160. https://doi.org/10.1111/j.1095-8312.1987.tb01986.x 
Allegrucci, G., Minasi, M.G., Sbordoni, V., 1997. Patterns of gene flow and genetic structure in cavedwelling crickets of the Tuscan endemic, Dolichopoda schiavazzii (Orthoptera, Rhaphidophoridae). Heredity, 78, 665-673. https://doi.org/10.1038/hdy.1997.106

Buhay, J.E., Crandall, K.A., 2005. Subterranean phylogeography of freshwater crayfishes shows extensive gene flow and surprisingly large population sizes. Molecular Ecology, 14, 4259-4273. https://doi.org/10.1111/j.1365-294X.2005.02755.x

Carchini, G., Rampini, M., Sbordoni, V., 1994. Life cycle and population ecology of the cave cricket Dolichopoda geniculata (Costa) from Valmarino cave (Central Italy). International Journal of Speleology, 23, 3-4. https://doi.org/10.5038/1827-806X.23.3.6

Chintauan-Marquier, I.C., Legendre, F., Hugel, S., Robillard, T., Grandcolas, et al., 2016. Laying the foundations of evolutionary and systematic studies in crickets (Insecta, Orthoptera): a multilocus phylogenetic analysis. Cladistics, 32, 1-28. https://doi.org/10.1111/cla.12114

Chopard, L., 1929. Note sur les Orthoptères cavernicoles du Tonkin. Bulletin de la Societé de Zoologie de France, 54, 224-238.

Chopard, L., 1934. Études zoologiques sur le Sahara Central; Orthoptère. Bulletin de la Société d'Histoire Naturelle d'Afrique du Nord, 4, 115-116.

Chopard, L., 1948. Three new species of Gryllidae (Orthoptera) from Arabia. Proceedings of the Royal Entomological Society of London. Series B, Taxonomy, 17(1-2), 1-4.

https://doi.org/10.1111/j.1365-3113.1948.tb00874.x

Chopard, L., 1968. Pars 12. Fam. Gryllidae: Subfam. Mogoplistinae, Myrmecophilinae, Scleropterinae, Cachoplistinae, Pteroplistinae, Pentacentrinae, Phalangopsinae, Trigonidiinae, Eneopterinae. Fam. Oecanthidae, Gryllotalpidae. Dr. W. Junk N.V., s Gravenhage, 215-500 p.

Cigliano, M., Braun, H., Eades, D.C., Otte, D., 2020. Orthoptera species file online, Version, 5.0.

http://orthoptera.speciesfile.org/

Cooper, S.J., Bradbury, J.H., Saint, K.M., Leys, R., Austin, A.D., Humphreys, W.F., 2007. Subterranean archipelago in the Australian arid zone: mitochondrial DNA phylogeography of amphipods from central Western Australia. Molecular Ecology, 16, 1533-1544. https://doi.org/10.1111/j.1365-294X.2007.03261.x

Culver, D.C., Kane, T.C., Fong, D.W., 1995. Adaptation and natural selection in caves: the evolution of Gammarus minus. Harvard University Press, Cambridge, 223 p. https://doi.org/10.4159/harvard.9780674419070

Culver, D.C., Pipan, T., 2009a. The biology of caves and other subterranean habitats. Oxford University Press, Oxford, 254 p.

Culver, D.C., Pipan, T., 2009b. Caves, as islands. In: Gillespie, R., Gillespie, R.G., Clague, D.A, (Eds.), Encyclopedia of islands. University of California Press, Berkeley, p. 150-153.

https://doi.org/10.1525/9780520943728-035

Di Russo, C., Vellei, A., Carchini, G., Sbordoni, V., 1987. Life cycle and age structure of Dolichopoda populations (Orthoptera, Raphidophoridae) from natural and artificial cave habitats. Italian Journal of Zoology, 54, 337-340.

https://doi.org/10.1080/11250008709355606

Drummond, A.J., Rambaut, A., 2007. BEAST: Bayesian evolutionary analysis by sampling trees. BMC Evolutionary Biology, 7, 214.

https://doi.org/10.1186/1471-2148-7-214
Finlay, J., Buhay, J., Crandall, K., 2006. Surface to subsurface freshwater connections: phylogeographic and habitat analyses of Cambarus tenebrosus, a facultative cave-dwelling crayfish. Animal Conservation, 9, 375-387.

https://doi.org/10.1111/j.1469-1795.2006.00046.x

Fujisawa, T., Vogler, A.P., Barraclough, T.G., 2015. Ecology has contrasting effects on genetic variation within species versus rates of molecular evolution across species in water beetles. Proceedings of the Royal Society B, 282, 2014-2476.

https://doi.org/10.1098/rspb.2014.2476

Funk, D.J., Omland, K.E., 2003. Species-level paraphyly and polyphyly: frequency, causes, and consequences, with insights from animal mitochondrial DNA. Annual Review of Ecology, Evolution, and Systematics, 34, 397-423. https://doi.org/10.1146/annurev.ecolsys.34. $\underline{011802.132421}$

Gorochov, A.V., 1979. Crickets of the genera Tartarogryllus and Modicogryllus (Orthoptera, Gryllidae) in Soviet Central Asia. Entomological Review, 57, 64-69.

Gorochov, AV., 1980. Crickets of the genera Eremogryllodes Chop. and Myrmecophilus Berth. (Orthoptera, Gryllidae) and systematic position of the tribe Bothriophylacini. Entomological Review, 59, 287-293.

Guzik, M., Cooper, S., Humphreys, W., Austin, A., 2009. Fine-scale comparative phylogeography of a sympatric sister species triplet of subterranean diving beetles from a single calcrete aquifer in Western Australia. Molecular Ecology, 18, 3683-3698.

https://doi.org/10.1111/j.1365-294X.2009.04296.x

Hubbell, T.H., Norton, R.M., 1978. The systematics and biology of the cave-crickets of the North American tribe Hadenoecini (Orthoptera: Saltatoria: Ensifera: Rhaphidophoridae: Dolichopodinae). Miscellaneous publications, Museum of Zoology, University of Michigan, no. 156.

Hall, T., Biosciences, I., Carlsbad, C., 2011. BioEdit: an important software for molecular biology. GERF Bulletin of Biosciences, 2, 60-61.

Juan, C., Guzik, M.T., Jaume, D., Cooper, S.J., 2010. Evolution in caves: Darwin's 'wrecks of ancient life' in the molecular era. Molecular Ecology, 19, 3865-3880. https://doi.org/10.1111/j.1365-294X.2010.04759.x

Komatsu, T., Maruyama, M., Ueda, S., Itino, T., 2008. mtDNA phylogeny of Japanese ant crickets (Orthoptera: Myrmecophilidae): diversification in host specificity and habitat use. Sociobiology, 52, 553-565.

Lejeusne, C., Chevaldonné, P., 2006. Brooding crustaceans in a highly fragmented habitat: the genetic structure of Mediterranean marine cave-dwelling mysid populations. Molecular Ecology, 15, 4123-4140. https://doi.org/10.1111/j.1365-294X.2006.03101.x

Librado, P., Rozas, J., 2009. DnaSP v5: a software for comprehensive analysis of DNA polymorphism data. Bioinformatics, 25, 1451-1452.

https://doi.org/10.1093/bioinformatics/btp187

Maddison, W.P., Maddison, D.R., 2018. Mesquite: a modular system for evolutionary analysis. Version 3.51 (http://www.mesquiteproject.org)

Miller, M.A., Pfeiffer, W., Schwartz, T., 2010. Creating the CIPRES Science Gateway for inference of large phylogenetic trees. Gateway Computing Environments Workshop (GCE), Institute of Electrical and Electronics Engineers, p. 1-8.

Nylander, J. A.A. 2004. MrModeltest v2. Program distributed by the author. Evolutionary Biology Centre, Uppsala University. 
Pfenninger, M., Schwenk, K., 2007. Cryptic animal species are homogeneously distributed among taxa and biogeographical regions. BMC Evolutionary Biology, 7, 121. https://doi.org/10.1186/1471-2148-7-121

Prous, X., Ferreira, R.L. \& Martins, R.P. Ecotone delimitation: epigean-hypogean transition in cave ecosystems. Austral Ecology 29, 374-382 (2004). https://doi.org/10.1111/j.1442-9993.2004.01373.x

Robillard, T., Desutter-Grandcolas, L., 2006. Phylogeny of the cricket subfamily Eneopterinae (Orthoptera, Grylloidea, Eneopteridae) based on four molecular loci and morphology. Molecular Phylogenetics and Evolution, 40, 643-661.

https://doi.org/10.1016/j.ympev.2005.10.019

Song, H., Amedegnato, C., Cigliano, M.M, Grandcolas, L.D., Heads, S.W., Huang Y., Otte D., Whiting, M.F., 2015. 300 million years of diversification: elucidating the patterns of orthopteran evolution based on comprehensive taxon and gene sampling. Cladistics, 31, 621-651. https://doi.org/10.1111/cla.12116

Swofford, D.L., 2002 PAUP*-Phylogenetic Analysis Using Parsimony (*and other methods). Ver. 4.0b10. Sinauer Associates, Sunderland, Massachusetts. https://doi.org/10.1111/j.0014-3820.2002.tb00191.x

Tahami, M.S., Merkl, O., Sadeghi, S., 2016. Leptodes of Iran, with description of six new cavernicolous species (Coleoptera: Tenebrionidae: Pimeliinae: Leptodini). Annales Zoologici, 66, 589-606.

https://doi.org/10.3161/00034541A NZ2016.66.4.012

Tahami, M.S., Gorochov, A.V., Sadeghi, S., 2017. Cave and burrow crickets of the subfamily Bothriophylacinae (Orthoptera: Myrmecophilidae) in Iran and adjacent countries. Zoosystematica Rossica, 26, 241-275. https://doi.org/10.31610/zsr/2017.26.2.241

Tahami, M.S., Gorochov, A.V., Sadeghi, S. 2018. Two new species of cave crickets of the genus Eremogryllodes (Orthoptera: Myrmecophilidae: Bothriophylacinae) from Iran. Zoosystematica Rossica, 27 322-327. https://doi.org/10.31610/zsr/2018.27.2.322
Tamura, K., Peterson, D., Peterson, N., Stecher, G., Nei, M., Kumar, S., 2011. MEGA5: molecular evolutionary genetics analysis using maximum likelihood, evolutionary distance, and maximum parsimony methods. Molecular Biology and Evolution, 28, 27312739. https://doi.org/10.1093/molbev/msr121

Taylan, M.S., Di Russo, C., Rampini, M., Ketmaier, V., 2013. Molecular systematics of the genus Troglophilus (Rhaphidophoridae, Orthoptera) in Turkey: mitochondrial 16S rDNA evidences. ZooKeys, 33-46. https://doi.org/10.3897/zookeys.257.4133

Taylan, M.S., Şirin, D., 2016. Speciation of the genus Dolichopoda in Anatolia with reference to the role of ancient central lake system. Insect Systematics and Evolution. 473, 267-283.

https://doi.org/10.1163/1876312X-47032143

Taylor, S.J., Weckstein, J.D., Takiya, D.M., Krejca, J.K., Murdoch, J.D., Veni, G., et al., 2007. Phylogeography of cave crickets (Ceuthophilus spp.) in central Texas: A keystone taxon for the conservation and management of federally listed endangered cave arthropods. Illinois Natural History Survey Technical Report, 58, 1-45.

Wiens, J.J., Chippindale, P.T., Hillis, D.M., 2003. When are phylogenetic analyses misled by convergence? A case study in Texas cave salamanders. Systematic Biology, 52, 501-514.

https://doi.org/10.1080/10635150390218222

Zhou, Z., Ye, H., Huang, Y., Shi, F., 2010. The phylogeny of Orthoptera inferred from mtDNA and description of Elimaea cheni (Tettigoniidae: Phaneropterinae) mitogenome. Journal of Genetics and Genomics, 37, 315-324.

https://doi.org/10.1016/S1673-8527(09)60049-7

Zhou, Z., Zhao, L., Liu, N., Guo, H., Guan, B., Di, J., Shi, F., 2017. Towards a higher-level Ensifera phylogeny inferred from mitogenome sequences. Molecular Phylogenetics and Evolution, 108, 22-33. https://doi.org/10.1016/j.ympev.2017.01.014 